\title{
Morphological Study of Human Cadaveric Liver and its Surgical Significance
}

\begin{abstract}
Introduction: The liver is the largest organ of the abdominal viscera. Knowledge of anatomy of liver and its variations is indispensable for accurate diagnosis of cases by radiologists, and prevention of unwanted surgical complications by surgeons. Many researchers have studied the segmental anatomy of the liver, but there are very few studies regarding the surface variations of liver.
\end{abstract}

Aim: To document the surface variations of liver and discuss them from clinical perspective.

Materials and Methods: This observational cross-sectional study was conducted from August 2015 to May 2019 on 50 liver specimens in the Department of Anatomy, Vardhman Mahavir Medical College. These livers were observed for any surface variations such as abnormal fissures or lobes, elongation or hypoplasia of lobes, etc. Data were tabulated and stats were calculated in percentages. Descriptive analysis of data has been carried out and mentioned in the study.
Results: In the present study, out of 50 liver specimens, variations were observed in $42(84 \%)$ specimens. Accessory fissures were seen in 16 (32\%) specimens. Elongated left lobe was present in $7(14 \%)$ specimens. Pons hepatis, which is a bridge of tissue connecting the quadrate lobe and the left lobe was observed in $8(16 \%)$ specimens. Caudate lobe variations observed in this study were abnormal fissures and hypertrophied papillary process.

Conclusion: The present study documents frequent morphological variations of liver such as elongated left lobe, accessory lobes, etc. Elongated left lobe may be related to fundus of stomach which should be kept in mind during left lobe resection. The radiologists can confuse accessory lobes or projections with pathological mass. Knowledge of these variations will undoubtedly help radiologists and surgeons to prevent misdiagnosis of cases and plan newer and safer surgical procedures.

\section{INTRODUCTION}

The liver is the largest of the abdominal viscera. It occupies most of the right hypochondrium and epigastrium, and frequently extends into the left hypochondrium as far as the left anterior axillary line. Anatomically, the liver is divided into right and left lobes by the attachment of falciform ligament, fissure for ligamentum teres and fissure for ligamentum venosum. The quadrate lobe is bounded by gall bladder fossa to the right, a short portion of inferior border anteriorly, the fissure for ligamentum teres to the left, and porta hepatis posteriorly. The caudate lobe is visible as a prominence to the right of fissure for ligamentum venosum, and posterior to porta hepatis. To its right, is groove for Inferior Vena Cava (IVC) [1].

The physiological lobes are separated by plane passing on anterosuperior surface along a line joining cystic notch to groove for IVC. The right lobe is subdivided into anterior and posterior segments, and left lobe into medial and lateral segments. Reidel's lobe is tongue like projection from inferior border of liver.

Hepatic imaging is done to detect primary and metastatic hepatic carcinoma. The major fissures on liver serve as important landmarks to delineate the boundaries of hepatic mass and extent of involvement of lobes [2]. Knowledge of liver variations is indispensable for accurate diagnosis of cases by radiologists, and prevention of unwanted surgical complications by surgeons. The surgeon may confuse a small accessory lobe with a lymph node and remove it during surgery leading to bleeding due to vascular damage [3]. Hypertrophied papillary process may be confused with an enlarged porta hepatis node on imaging. The radiologists can confuse accessory lobes or projections with pathological mass. Knowledge of variations in morphology of liver will undoubtedly help radiologists and surgeons to prevent misdiagnosis of cases and plan newer and safer surgical procedures. Hence, this study was done to document the surface variations of liver and discuss them from clinical perspective.

\section{MATERIALS AND METHODS}

The observational cross-sectional study was conducted on 50 liver specimens in the Department of Anatomy, Vardhman Mahavir Medical College and Safdarjung Hospital, New Delhi, India. The specimens were obtained from cadavers used for undergraduate teaching from August 2015 to May 2019.

The specimens were removed from adult human cadavers during routine dissection for abdomen and then preserved in 10\% formalin. These livers were observed for any surface variations such as abnormal fissures or lobes, elongation or hypoplasia of lobes, etc. Photographs of the variations were taken and results were tabulated. The specimens showing any evidence of disease or surgery were excluded from the study.

\section{STATISTICAL ANALYSIS}

The collected data was tabulated and percentages were calculated by Microsoft Excel. Descriptive analysis has been carried out and mentioned in the study.

\section{RESULTS}

In the present study, out of 50 liver specimens, variations were observed in 42 (84\%) specimens [Table/Fig-1]. Accessory fissures were seen in 16 (32\%) specimens [Table/Fig-2-4]. The fissures were observed mainly on antero-superior surface (7 specimens). Variations of left lobe encountered in the study were elongated left lobe [Table/Fig-5], lingular projection [Table/Fig-6] and hypoplastic left lobe [Table/Fig-7]. Elongated left lobe was present in 7 (14\%) 
specimens. Pons hepatis, which is a bridge of tissue connecting the quadrate lobe and the left lobe was observed in $8(16 \%)$ specimens [Table/Fig-8]. Caudate lobe variations observed in this study were abnormal fissures and hypertrophied papillary process [Table/Fig-9]. Other documented variations like Riedel's lobe, variation in the attachment of Ligamentum teres, Fissure for ligamentum venosum and structures arrangement in the porta hepatis were not found in the present study.

\begin{tabular}{|l|l|c|c|}
\hline \multicolumn{2}{|l|}{ Variations } & Number & $\%$ \\
\hline \multirow{3}{*}{$\begin{array}{l}\text { Accessory } \\
\text { fissures }\end{array}$} & Anterosuperior surface & 7 & 14 \\
\cline { 2 - 4 } & Caudate lobe & 6 & 12 \\
\cline { 2 - 4 } & Posteroinferior surface of left lobe & 3 & 6 \\
\hline Elongated left lobe & 7 & 14 \\
\hline Lingular projection of left lobe & 2 & 4 \\
\hline Hypoplastic left lobe & 3 & 6 \\
\hline Pons hepatis & 8 & 16 \\
\hline Hypertrophied papillary process & 6 & 12 \\
\hline
\end{tabular}

[Table/Fig-1]: Table showing the types of variations observed in present study.
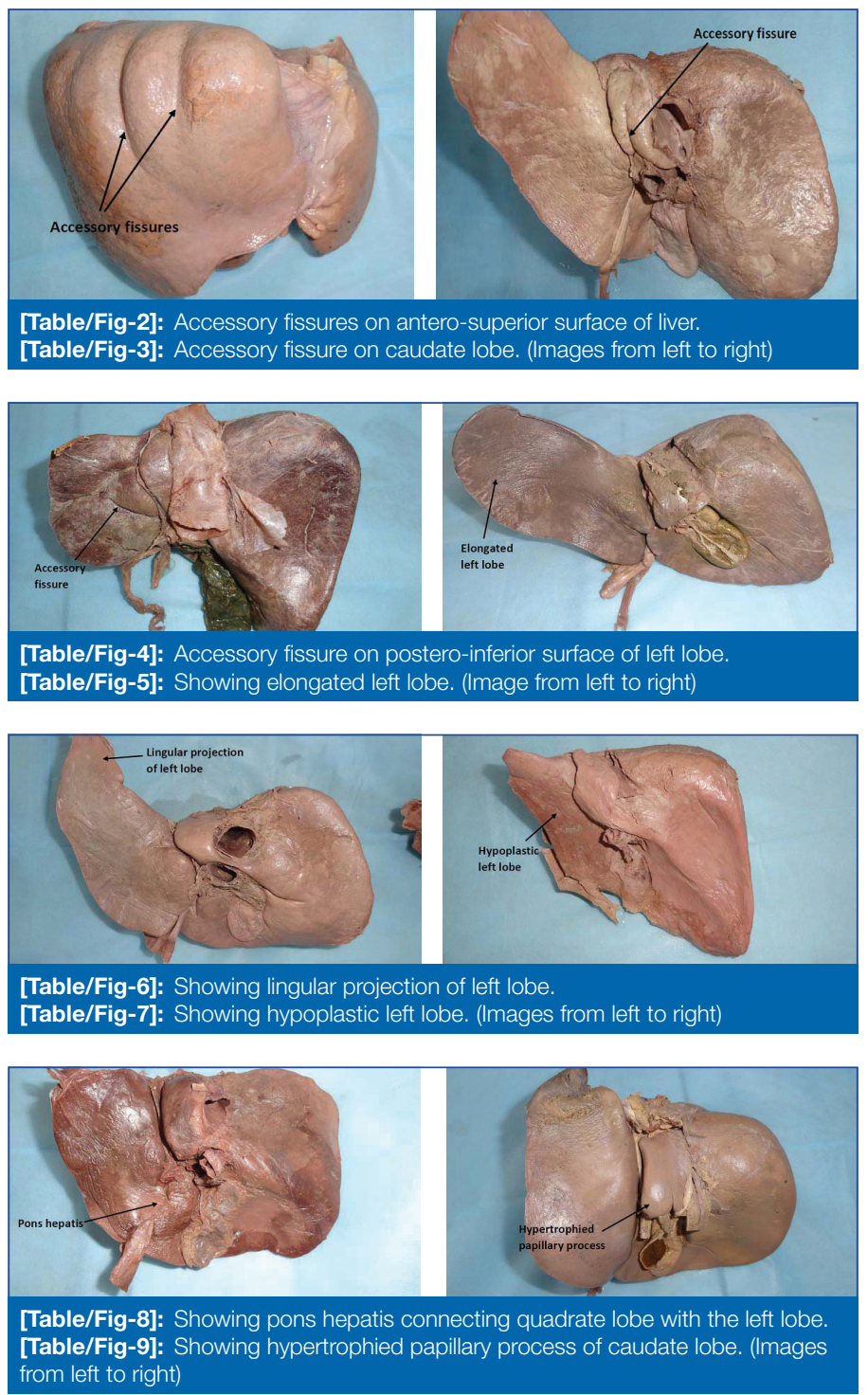

\section{DISCUSSION}

The accessory fissures of liver were encountered in $32 \%$ cases in the present study [Table/Fig-10] [3-7]. Joshi SD et al., reported a similar percentage (30\%) [4]. Singh HR and Rabi S (81.42\%) reported a higher percentage, whereas Muktyaz $\mathrm{H}$ et al., (12.1\%) reported a lower percentage $[5,6]$. When there is collection of fluid in the fissures, the radiologist may confuse it with an intrahepatic cyst, haematoma or abscess. Metastatic tumour cells getting lodged into these fissures may look like an intrahepatic mass [8]. Multiple accessory fissures may mimic pathologic macronodular liver on CT [9].

\begin{tabular}{|l|c|c|c|c|c|c|}
\hline & $\begin{array}{c}\text { Patil S } \\
\text { et al., } \\
\text { [3] }\end{array}$ & $\begin{array}{c}\text { Joshi } \\
\text { SD et } \\
\text { al., [4] }\end{array}$ & $\begin{array}{c}\text { Singh HR } \\
\text { and Rabi } \\
\text { S [5] }\end{array}$ & $\begin{array}{c}\text { Muktyaz } \\
\text { H et al., } \\
\text { [6] }\end{array}$ & $\begin{array}{c}\text { Chaudhari } \\
\text { HJ et al., [7] }\end{array}$ & $\begin{array}{c}\text { Present } \\
\text { study }\end{array}$ \\
\hline $\begin{array}{l}\text { Accessory } \\
\text { fissures }\end{array}$ & $10 \%$ & $30 \%$ & $81.42 \%$ & $12.1 \%$ & $12.5 \%$ & $32 \%$ \\
\hline Pons hepatis & $10 \%$ & $30 \%$ & $22.86 \%$ & - & $1.25 \%$ & $16 \%$ \\
\hline $\begin{array}{l}\text { Elongated left } \\
\text { lobe }\end{array}$ & - & - & $12.86 \%$ & - & $12.5 \%$ & $14 \%$ \\
\hline $\begin{array}{l}\text { Hypertrophied } \\
\text { papillary process }\end{array}$ & - & $32 \%$ & $4.29 \%$ & - & $1.25 \%$ & $12 \%$ \\
\hline \\
[Table/Fig-10]: Showing the comparison between present study and other studies \\
[3-7].
\end{tabular}

It was earlier postulated that fissures on the diaphragmatic surface could be due to invagination of the musculature of the diaphragm into the liver on the costal surface $[9,10]$. But, recent radiological study has shown that these represent portal fissures on surface [7]. Macchi $V$ et al., suggested that diaphragmatic sulci can serve as good landmark for projection of the portal fissures and of the hepatic veins with their tributaries running through them [11].

Variations of left lobe encountered in the present study included elongated left lobe, lingular projection and hypoplastic left lobe. Knowledge of left lobar anatomy and its relations is essential for surgeons during hepatectomy and left lobar mass removal. Elongated left lobe may be related to fundus of stomach which should be kept in mind during left lobe resection. Abnormal development of left lobe may predispose to gastric volvulus and diaphragmatic hernia [12]. The liver specimens with elongated left lobe were similar to saddle like liver described by Netter FH (Netter type 3) [Table/Fig-11] [13].

\begin{tabular}{|l|l|}
\hline Types & \multicolumn{1}{|c|}{ Characterstics } \\
\hline Type 1 & Very small left lobe, deep costal impressions \\
\hline Type 2 & Complete atrophy of left lobe \\
\hline Type 3 & Transverse saddle like liver, relatively large left lobe \\
\hline Type 4 & Tongue like process of right lobe \\
\hline Type 5 & Very deep renal impression and corset constriction \\
\hline Type 6 & Diaphragmatic grooves \\
\hline [Table/Fig-11]: Netter's classification of liver [13].
\end{tabular}

Pons hepatis is a bridge of liver tissue connecting the quadrate lobe with the left lobe across the fissure for ligamentum teres. Thus, pons hepatis obscures this fissure resulting in unclear separation of left and right anatomical lobes. Because of this, the surgeon may face difficulty in lobectomy operations. Also, the radiologist would not be able to properly demarcate the extent of an intrahepatic mass. The pons hepatis was observed in $16 \%$ cases in the present study. Chaudhari $\mathrm{HJ}$ et al., reported a much lower percentage (1.25\%) [Table/Fig-10] [7].

Caudate lobe variations have assumed importance because caudate lobe resections alone or combined with major hepatectomy operations have increased now-a-days. Cases of hepatocellular or hilar bile duct carcinoma require this procedure. Hypertrophied papillary process may be confused with an enlarged porta hepatis node on imaging. Projection of papillary process downward and to the left may also mimic a pancreatic mass [8]. Chaudhari HJ et al., (1.25\%) and Nayak BS et al., (1.81\%) reported a much lower percentage of large papillary process $[7,14]$.

\section{Limitation(s)}

The variations were not classified based on age and sex of the cadavers.

\section{CONCLUSION(S)}

The present study documents frequent morphological variations of liver. Multiple accessory fissures may mimic pathologic macronodular 
liver on CT. Elongated left lobe may be related to fundus of stomach which should be kept in mind during left lobe resection. The presence of pons hepatis may result in unclear separation of left and right anatomical lobes. Because of this, the surgeon may face difficulty in lobectomy operations. Hypertrophied papillary process may be confused with an enlarged porta hepatis node on imaging. The radiologists can confuse accessory lobes or projections with pathological mass. Thus, knowledge of these variations will help radiologists and surgeons to prevent misdiagnosis of cases and plan newer and safer surgical procedures.

\section{REFERENCES}

[1] Standring S. Gray's Anatomy: The Anatomical Basis of Clinical Practice. $41^{\text {st }}$ ed. London: Elsevier. Liver. 1160-65.

[2] Sahani DU, Kalva SP. Imaging the liver. Oncologist. 2004;9(4):385-97.

[3] Patil S, Sethi M, Kakar S. Morphological study of human liver and its surgical importance. Int J Anat Res. 2014;2(2):310-14

[4] Joshi SD, Joshi SS, Athavale SA. Some interesting observations on the surface features of the liver and their clinical implications. Singap Med J. 2009;50 (7):718-19.
[5] Singh HR, Rabi S. Study of morphological variations of liver in human. Translational Research in Anatomy. 2019;14:1-5. DOI: 10.1016/j.tria.2018.11.004.

[6] Muktyaz H, Nema U, Suniti RM, Mahboobul H. Anatomical study of accessory sulci of liverand its clinical significance in north Indian population.. Int $\mathrm{J}$ Med Health Sci. 2013;2(20):224-29.

[7] Chaudhari HJ, Ravat MK, Vaniya VH, Bhedi AN. Morphological study of human liver andits surgical importance. J Clin Diagn Res. 2017;11:AC09-12. doi: 10.7860/ JCDR/2017/24467.10020.

[8] Auh YH, Rubenstein WA, Zirinsky K, Kneeland JB. Accessory fissures of the live: CT and sonographic appearance. Am J Roentgenol. 1984;143(3):565-72.

[9] Saritha S, Ramani, Nagajyothi, Yesender. Cadaveric study of morphological variations in the human liver and its clinical importance. Int $\mathrm{J}$ Med Sci Clin Inventions. 2015;2(6):1020-31.

[10] Thompson A. The morphological significance of certain fissures in the human liver. J Anat Physio. 1899:33:22.

[11] Macchi V, Feltrin G, Parenti A, De Caro R. Diaphragmatic sulci and portal fissures. J Anat. 2003;202(3):303-08.

[12] Daver GB, Bakhshi GD, Patil A, Ellur S, Jain M, Daver NG. Bifid liver in a patient with diaphragmatic hernia. Indian J Gastroenterol. 2005;24(1):27-28.

[13] Netter FH. Atlas of Human Anatomy. 2ed. New York: 18 Guilford Press, 2000.

[14] Nayak BS. A study on the anomalies of liver in the south Indian cadavers. Int $J$ Morphol. 2013;31(2):658-61.

\section{PARTICULARS OF CONTRIBUTORS:}

1. Senior Resident, Department of Anatomy, Vardhman Mahavir Medical College and Safdarjung Hospital, New Delhi, India.

2. Junior Resident, Department of Anatomy, Vardhman Mahavir Medical College and Safdarjung Hospital, New Delhi, India.

3. Associate Professor, Department of Anatomy, Vardhman Mahavir Medical College and Safdarjung Hospital, New Delhi, India.

4. Director and Professor, Department of Anatomy, Vardhman Mahavir Medical College and Safdarjung Hospital, New Delhi, India.

NAME, ADDRESS, E-MAIL ID OF THE CORRESPONDING AUTHOR:

Dr. Mahendra Ambadasji Kathole,

DB-302, Block-3A, Transit Flats, Hudco Place Extension,

Andrews Ganj, New Delhi-110049, India.

E-mail: mahendrakathole@gmail.com

\section{AUTHOR DECLARATION:}

- Financial or Other Competing Interests: None

- Was Ethics Committee Approval obtained for this study? NA

- Was informed consent obtained from the subjects involved in the study? NA

- For any images presented appropriate consent has been obtained from the subjects. NA
PLAGIARISM CHECKING METHODS: [Jain Het al.]

- Plagiarism X-checker: Aug 02, 2020

- Manual Googling: Oct 15, 2020

- iThenticate Software: Jan 15, $2021(19 \%)$
ETYMOLOGY: Author Origin

Date of Submission: Aug 01, 2019 Date of Peer Review: Sep 11, 2020 Date of Acceptance: Oct 20, 2020 Date of Publishing: Apr 01, 2021 